\title{
Aerosol optical properties in the southeastern United States in summer - Part 2: Sensitivity of aerosol optical depth to relative humidity and aerosol parameters
}

\author{
Charles A. Brock ${ }^{1}$, Nicholas L. Wagner ${ }^{1,2}$, Bruce E. Anderson ${ }^{3}$, Andreas Beyersdorf ${ }^{3}$, Pedro Campuzano-Jost ${ }^{2,4}$, \\ Douglas A. Day ${ }^{2,4}$, Glenn S. Diskin ${ }^{3}$, Timothy D. Gordon ${ }^{1,2, a}$, Jose L. Jimenez ${ }^{2,4}$, Daniel A. Lack ${ }^{1,2, b}$, Jin Liao ${ }^{1,2, c}$, \\ Milos Z. Markovic $^{1,2, d}$, Ann M. Middlebrook ${ }^{1}$, Anne E. Perring ${ }^{1,2}$, Matthews S. Richardson ${ }^{1,2}$, Joshua P. Schwarz ${ }^{1}$, \\ Andre Welti ${ }^{1,2, \mathrm{e}}$, Luke D. Ziemba ${ }^{3}$, and Daniel M. Murphy ${ }^{1}$ \\ ${ }^{1}$ NOAA Earth System Research Laboratory, Boulder, Colorado, USA \\ ${ }^{2}$ Cooperative Institute for Research in Environmental Sciences, University of Colorado, Boulder, Colorado, USA \\ ${ }^{3}$ NASA Langley Research Center, Hampton, Virginia, USA \\ ${ }^{4}$ Department of Chemistry and Biochemistry, University of Colorado, Boulder, Colorado, USA \\ ${ }^{a}$ now at: Handix Scientific LLC, Boulder, Colorado, USA \\ ${ }^{\mathrm{b}}$ now at: TEAC Consulting, Brisbane, Australia \\ ${ }^{c}$ now at: NASA Goddard Space Flight Center, Greenbelt, Maryland, USA \\ d now at: Air Quality Research Division, Environment Canada, Toronto, Ontario, Canada \\ ${ }^{e}$ now at: Leibniz Institute for Tropospheric Research, Department of Physics, Leipzig, Germany
}

Correspondence to: Charles A. Brock (charles.a.brock@ noaa.gov)

Received: 13 October 2015 - Published in Atmos. Chem. Phys. Discuss.: 10 November 2015

Revised: 25 March 2016 - Accepted: 11 April 2016 - Published: 22 April 2016

\begin{abstract}
Aircraft observations of meteorological, trace gas, and aerosol properties were made between May and September 2013 in the southeastern United States (US). Regionally representative aggregate vertical profiles of median and interdecile ranges of the measured parameters were constructed from 37 individual aircraft profiles made in the afternoon when a well-mixed boundary layer with typical fair-weather cumulus was present (Wagner et al., 2015). We use these 0$4 \mathrm{~km}$ aggregate profiles and a simple model to calculate the sensitivity of aerosol optical depth (AOD) to changes in dry aerosol mass, relative humidity, mixed-layer height, the central diameter and width of the particle size distribution, hygroscopicity, and dry and wet refractive index, while holding the other parameters constant. The calculated sensitivity is a result of both the intrinsic sensitivity and the observed range of variation in these parameters. These observationally based sensitivity studies indicate that the relationship between AOD and dry aerosol mass in these conditions in the southeastern US can be highly variable and is especially sensitive to relative humidity (RH). For example, calculated
\end{abstract}

AOD ranged from 0.137 to 0.305 as the $\mathrm{RH}$ was varied between the 10th and 90th percentile profiles with dry aerosol mass held constant. Calculated AOD was somewhat less sensitive to aerosol hygroscopicity, mean size, and geometric standard deviation, $\sigma_{\mathrm{g}}$. However, some chemistry-climate models prescribe values of $\sigma_{\mathrm{g}}$ substantially larger than we or others observe, leading to potential high biases in modelcalculated AOD of $\sim 25 \%$. Finally, AOD was least sensitive to observed variations in dry and wet aerosol refractive index and to changes in the height of the well-mixed surface layer. We expect these findings to be applicable to other moderately polluted and background continental air masses in which an accumulation mode between $0.1-0.5 \mu \mathrm{m}$ diameter dominates aerosol extinction. 


\section{Introduction}

Aerosols in the atmosphere scatter and absorb solar radiation and alter the earth's energy balance. The magnitude and variation in this aerosol direct radiative effect has large uncertainties that are being addressed by numerous observational and modeling studies. Key to these investigations, measurements of AOD, the vertically integrated aerosol extinction coefficient $\left(\sigma_{\text {ext }}\right)$, provide information on the spatial and temporal distribution of the atmospheric aerosol. Long-term remote sensing measurements of AOD made by ground-based networks such as the AERONET sunphotometers (Holben et al., 2001) and by space-based instruments (Kahn, 2011) have produced a global record showing the spatial and temporal variation in AOD. These observations are often used to evaluate and constrain earth system models that simulate aerosol emissions, formation, processing, and removal. For such comparisons, the models must convert their simulated aerosol parameters to optical extinction and then vertically integrate to compare with measured AOD values. These models typically track dry aerosol mass using bulk, modal, or binned microphysical schemes and then calculate ambient extinction based on assumed or simulated particle diameter, width of the size distribution, and the hygroscopic uptake of water (Liu et al., 2012). Conversely, there are active efforts to assimilate AOD measurements for use by air quality models that predict dry aerosol mass (usually $\mathrm{PM}_{2.5}$, aerosol mass of particles smaller than $2.5 \mu \mathrm{m}$ diameter; Benedetti et al., 2009; Saide et al., 2014). In these cases the remotely sensed AOD measurements must be converted to an in situ dry mass concentration at a specific altitude, usually using prescribed aerosol characteristics based on limited prior in situ measurements.

Aerosol optical depth is dependent upon several aerosol characteristics in addition to mass, the parameter that is often of interest. Many particles are composed of compounds that can take up water with increasing atmospheric relative humidity (RH). This hygroscopic water uptake changes particle size and refractive index and can lead to dramatic changes in the extinction as a function of RH, even when dry aerosol mass is constant. Since atmospheric RH is highly variable temporally, horizontally, and especially vertically, aerosol water plays an important role in establishing the relationship between ambient extinction (or AOD) and dry aerosol mass. As van Donkelaar et al. (2015) succinctly state, "the relationship between AOD and [ground-level] $\mathrm{PM}_{2.5}$ depends on aerosol vertical distribution, humidity, and aerosol composition, which are impacted by changes in meteorology and emissions". Perhaps less recognized by some researchers, aerosol extinction is also quite sensitive to particle diameter because the extinction cross section increases sharply with increasing diameter. Similarly, the width of the size distribution (usually described by the geometric standard deviation, $\sigma_{\mathrm{g}}$ ) describes how particle concentration varies as a function of diameter, and thus affects the optical extinction for a given aerosol mass concentration. The refractive index of the particles, influenced by the aerosol water content, also affects the amount of extinction produced by a particle of a given total mass.

Globally averaged, dust, sea salt, biomass burning, and anthropogenic aerosols dominate AOD (e.g., Boucher et al., 2013; Jacobson, 2001). Between and within each of these aerosol categories there are substantial variations in particle diameter and shape, hygroscopicity, size distribution width, mixing state, and refractive index, as well as in the vertical distribution of these properties. Because of these confounding influences, the relationship between AOD and dry aerosol mass is expected to vary in different regions and seasons.

Several studies have examined the relationship between detailed aerosol characteristics and the direct aerosol radiative effect, ambient extinction, or AOD. Hegg et al. (1993) examined the sensitivity of ambient extinction to particle diameter and refractive index. They found that extinction was particularly sensitive to the initial dry size of the aerosol prior to hygroscopic growth. McComiskey et al. (2008) evaluated in detail how aerosol intensive properties affected the top of the atmosphere and surface radiation for a wide range of aerosol types, finding the greatest sensitivity to the aerosol single-scattering albedo. Magi et al. (2005) used airborne in situ measurements in the eastern US to estimate the contribution of dry particulate constituents and aerosol water to AOD. Koloutsou-Vakakis et al. (1998) found that aerosol composition and hygroscopicity were important in relating aerosol mass concentration measurements to ambient scattering. Using airborne and remote sensing measurements, Crumeyrolle et al. (2014) showed a strong relationship between AOD and surface and in situ aerosol mass concentrations in the eastern US. Ziemba et al. (2013) report good closure between remotely sensed profiles of aerosol extinction and in situ measurements taken in the eastern US when aerosol hygroscopic growth was taken into account. Esteve et al. (2012) found that uncertainty in hygroscopic growth was likely the largest contributor of discrepancies between AOD determined from remote sensing and from in situ measurements. Esteve et al. (2016) used measurements and a radiative transfer model to determine that the aerosol direct radiative effect in western Europe in spring was moderately sensitive to the size distribution of the aerosol and less so to the refractive index of the particles. Several global modeling studies have found strong sensitivities of the direct aerosol radiative effect to particle size, composition, and hygroscopicity (e.g., Adams et al., 2001; Boucher and Anderson, 1995; Nemesure et al., 1995; Pilinis et al., 1995). Adams et al. (2001) used global model simulations to demonstrate that the water content of the aerosol, especially for $\mathrm{RH}>90 \%$, plays an important role in altering the aerosol direct radiative effect, and that hygroscopicity and the RH field must be well described in climate models. More detailed studies using both measurements and modeling suggest that high RH near clouds can substantially enhance the aerosol extinction at spatial scales 
that are unresolved by climate models and some remote sensing measurements (e.g., Bar-Or et al., 2012; Haywood et al., 1997; Koren et al., 2007; Twohy et al., 2009).

In this study we focus on the relationship between measured aerosol properties and calculated AOD for a specific aerosol type, the submicron-dominated mixed organicsulfate aerosol typical of moderately polluted and background continental air. This type of aerosol is found in several regions globally, including southern Africa, Eurasia, and South America (e.g., Vakkari et al., 2013). A companion paper (Part 1; Brock et al., 2016) uses detailed in situ airborne measurements of dry aerosol composition, dry size distribution and change in optical extinction as a function of relative humidity, $f(\mathrm{RH})$, to examine the hygroscopicity of the aerosol in this environment. In Brock et al. (2016) it was found that observed $f(\mathrm{RH})$ could be described accurately using a physically based, single-parameter function. The fitted parameter, $\kappa_{\text {ext }}$, is related to but not identical to the chemically determined $\kappa_{\text {chem }}$ from the $\kappa$-Köhler theory of Petters and Kreidenweiss (2007). In Brock et al. (2016) we found that the value of $\kappa_{\text {chem }}$ for the dominant organic component must have been $<0.10$ to be consistent with the observed $f(\mathrm{RH})$ for $>75 \%$ of the cases examined.

In this analysis (Part 2), the $\kappa_{\text {ext }}$ parameterization developed in Brock et al. (2016) is used to determine ambient extinction. Vertical profiles of this ambient extinction are then integrated to calculate the AOD from the surface to the top of the profile, and the effects of aerosol mass, hygroscopicity, size distribution, refractive index, and vertical distribution on the AOD are evaluated. The purpose of this effort is to identify which parameters must be well simulated or observed to relate AOD to dry aerosol mass in this and similar environments. Similar studies are needed in regions with other aerosol types to develop a comprehensive understanding of the relationship between AOD, aerosol composition, shape, and size, and atmospheric RH to reduce uncertainty in aerosol radiative effects (Kahn, 2011).

\section{Methods}

\subsection{Instrumentation}

We analyze vertical profiles derived from airborne, in situ measurements from the May-July 2013 Southeastern Nexus of Air Quality and Climate (SENEX) and the portions of the August-September 2013 Study of Emissions and Atmospheric Composition, Clouds, and Climate Coupling by Regional Surveys (SEAC $\left.{ }^{4} \mathrm{RS}\right)$ projects that were carried out in the southeastern US. Details of the instruments, measurements, and methodology for generating regionally representative vertical profiles of aerosol, gas-phase, and meteorological parameters are given by Wagner et al. (2015) and may also be found in Brock et al. (2016). Measurements included the composition of the sub- $0.7 \mu \mathrm{m}$ non-refractory composition, the dry particle size distribution from $\sim 0.004$ to $1.0 \mu \mathrm{m}$, and aerosol extinction at $532 \mathrm{~nm}$ wavelength and three relative humidities $(\sim 15, \sim 70$, and $\sim 90 \%)$ on the humidified branch of the deliquescence/efflorescence curve. As described in Brock et al. (2016), the contribution to extinction due to particles with diameters $>0.7 \mu \mathrm{m}$ was found to be small and is ignored in this work. All values presented here, except for ambient extinction, have been corrected to standard temperature and pressure (STP) conditions, defined as 1 atmosphere and $273.15 \mathrm{~K}$.

\subsection{Creating aggregate vertical profiles}

Measurements were made in summer during periods when the NASA DC-8 (SEAC ${ }^{4}$ RS) and NOAA WP-3D (SENEX) aircraft were sampling the fully developed planetary boundary layer in fair-weather cumulus conditions. Such conditions are representative of the summertime lower troposphere in daytime in the southeastern US (Warren et al., 2007). As described in more detail by Wagner et al. (2015), individual profiles made over Mississippi, Alabama, and Georgia in the afternoon between 12:00 and 18:30 Central Daylight Time (CDT) were aggregated into $150 \mathrm{~m}$ vertical bins. Only 37 profiles (of 74 total) that showed a distinct and easily characterized vertical structure and that were made in the presence of fair-weather cumulus clouds were chosen for analysis. Three layers with distinct aerosol and gas-phase chemical characteristics were evident in the analyzed profiles: (1) a well-mixed layer extending from the surface to the vicinity of cloud base in which short-lived gas-phase species were nearly homogeneously distributed; (2) the free troposphere in the upper portion of the profile, with low mixing ratios of short-lived species and generally lower abundances of pollutants; and (3) a cloud layer, or transition layer, between the well-mixed layer and the free troposphere, displaying intermediate chemical lifetimes and mixing ratios that are a result of mixing between the well-mixed layer and the free troposphere.

From this complex vertical structure we wish to calculate representative vertical profiles of aerosol and meteorological parameters. However, direct altitude-based averaging of the individual profiles would combine air from the well-mixed layer, the transition layer, and the free troposphere because the heights of these layers varied from profile to profile. To avoid this problem, Wagner et al. (2015) defined a normalized altitude, $h_{\text {norm }}$, for each profile such that the top of the mixed layer, $h_{\mathrm{ML}}$, is assigned a normalized altitude of 1 , and the top of the transition layer, $h_{\mathrm{TL}}$, is assigned a normalized altitude of 2 :

$$
\begin{aligned}
& 0<h<h_{\mathrm{ML}}, h_{\text {norm }}=h / h_{\mathrm{ML}} \\
& h_{\mathrm{ML}}<h<h_{\mathrm{TL}}, h_{\text {norm }}=1+\left(h-h_{\mathrm{ML}}\right) /\left(h_{\mathrm{TL}}-h_{\mathrm{ML}}\right) \\
& h>h_{\mathrm{TL}}, h_{\text {norm }}-1+h / h_{\mathrm{TL}} .
\end{aligned}
$$

For each profile $h_{\mathrm{ML}}$ was defined as the highest altitude at which the virtual potential temperature was constant and 
above which there was a rapid reduction in the isoprene concentration. The value of $h_{\mathrm{TL}}$ was defined by a temperature inversion and a rapid decrease in the $\mathrm{CO}$ mixing ratio. The individual altitude-normalized profiles were averaged to produce an aggregate profile for each parameter of interest, with 10 normalized altitude bins in each layer. These aggregate profiles include median values, as well as the 10th, 25th, 75th, and 90th percentiles of each normalized altitude bin to describe atmospheric variability. To calculate AOD, the normalized altitudes of the aggregate profiles in Wagner et al. (2015) were converted back to average altitudebased profiles using the median values $h_{\mathrm{ML}}=1132 \mathrm{~m}$ and $h_{\mathrm{TL}}=2137 \mathrm{~m}$ above ground level (a.g.l.). The altitude bins of this aggregate profile are in increments of $113.2 \mathrm{~m}$ for the well-mixed layer, $100.5 \mathrm{~m}$ in the transition layer, and $213.7 \mathrm{~m}$ in the free troposphere. The resulting aggregate profiles are representative of the summertime, cumulus-topped fair-weather planetary boundary layer and lower free troposphere of the southeastern US when the daytime boundary layer is fully developed.

\subsection{Determining ambient extinction}

Ambient extinction must be estimated from measurements that are made inside the aircraft cabin under different thermodynamic conditions than the atmosphere. As described in Brock et al. (2016), the hygroscopic growth parameter $f(\mathrm{RH})$ is the ratio of ambient extinction $\sigma(\mathrm{RH})$ to extinction measured at the dry $\left(\mathrm{RH}_{0} \sim 15 \%\right)$ condition, $\sigma\left(\mathrm{RH}_{o}\right)$. The value of $f(\mathrm{RH})$ was calculated for each data point in three different ways. In the first method, $\kappa$-Köhler theory was applied to measurements of aerosol size distribution and composition to predict particle diameter as a function of RH. Mie theory was then used to predict the ambient extinction from the deliquesced particle size distribution. In the second method, the observed three-point $f(\mathrm{RH})$ values were used to fit a curve of the form

$$
\frac{\sigma(\mathrm{RH})}{\sigma\left(\mathrm{RH}_{0}\right)} \equiv f(\mathrm{RH})=\left[\frac{\left(100-\mathrm{RH}_{0}\right)}{(100-\mathrm{RH})}\right]^{\gamma}
$$

and the extinction at ambient $\mathrm{RH}$ was calculated using the fitted coefficient. Finally, a new parameterization of the form

$f(\mathrm{RH})=1+\kappa_{\text {ext }} \frac{\mathrm{RH}}{100-\mathrm{RH}}$

was fitted to the observed three-point $f(\mathrm{RH})$ values and the extinction at ambient RH calculated. The $\gamma$ parameterization, Eq. (2), has been widely used in previous studies (e.g., Attwood et al., 2014; Doherty, 2005; Kasten, 1969; Massoli et al., 2009; Quinn et al., 2005; Ziemba et al., 2013). However, the $\gamma$ parameterization did not fit the observed dependence of extinction with RH in the southeastern US as well as did the $\kappa_{\text {ext }}$ parameterization, Eq. (3), which was developed in Brock et al. (2016). In Sect. 3.3 we examine the sensitivity of calculated AOD to whether $\gamma$ or $\kappa_{\text {ext }}$ is chosen to parameterize $f(\mathrm{RH})$.

\section{Results and analysis}

\subsection{Vertical profiles}

The 37 individual profiles meeting the criteria described in Sect. 2.2 were combined into an aggregate profile following Eq. (1), from which 10th percentile, median (50th percentile), and 90th percentile values were calculated. Because the distribution of most parameters was not Gaussian, percentile values are used to represent the range of observed variability. Median values of STP-corrected dry aerosol extinction decreased from $\sim 60 \mathrm{Mm}^{-1}$ at the bottom of the aggregate profile to $\sim 40 \mathrm{Mm}^{-1}$ at the top of the transition layer $\sim 2100 \mathrm{~m}$ above ground level (Fig. 1a), with an abrupt decrease to $\sim 10 \mathrm{Mm}^{-1}$ in the free troposphere. Wagner et al. (2015) used gas-phase and aerosol tracers to show that this profile was the result of a well-mixed layer below cloud base at $\sim 1100 \mathrm{~m}$, a cloud or transition layer between $\sim 1100$ and $\sim 2100 \mathrm{~m}$, and the free troposphere above $\sim 2100 \mathrm{~m}$. Within the transition layer, Wagner et al. (2015) found a small but statistically significant increase of $\sim 15 \%$ in aerosol mass above the values expected from mixing alone. This enhancement was composed of roughly equal amounts of sulfate and organic mass and resulted in a higher sulfate mass fraction in this layer compared to the well-mixed layer below. Relative humidity increased from $\sim 60 \%$ at the lowest altitudes to a median value of $\sim 80 \%$ in the transition layer (Fig. 1b), with lower median RH but greater variability in the free troposphere. Ambient extinction (Fig. 1c) reached a maximum in the transition layer where RH was highest, with 90th percentile values $\sim 3$ times greater than the median values.

Aerosol optical depth was calculated between the surface and the top of the profile by integrating ambient extinction from the surface upward (Fig. 1d). The extinction within the well-mixed layer was extrapolated to the surface for each individual profile. Wagner et al. (2015) show that measurements of extinction at the Centreville, Alabama, surface site during the SENEX time period agreed with values measured at the lowest altitude of the aircraft, supporting such extrapolation. The median AOD at $532 \mathrm{~nm}$ was 0.19 . This value is similar to values of AOD at $532 \mathrm{~nm}$ of 0.19 and 0.17 at the AERONET (Holben et al., 2001) locations of Centreville, Alabama $(n=268)$, and Atlanta, Georgia $(n=48)$, respectively. These mean AERONET AOD values were made between 12:00 and 18:30 local time on the days included in this analysis, and the AOD at $532 \mathrm{~nm}$ was logarithmically interpolated using the Ångström exponent from measurements made at 500 and $675 \mathrm{~nm}$. This consistency between the AOD derived from the aircraft in situ measurements and that measured at the AERONET sites indicates that there were no significant aerosol layers above $4 \mathrm{~km}$ in most of the profiles measured, that the aggregated profiles are regionally representative, and that lower tropospheric extinction dominated regional AOD. Placed in the context of a multiyear AOD record from the Atlanta AERONET site, the data analyzed 

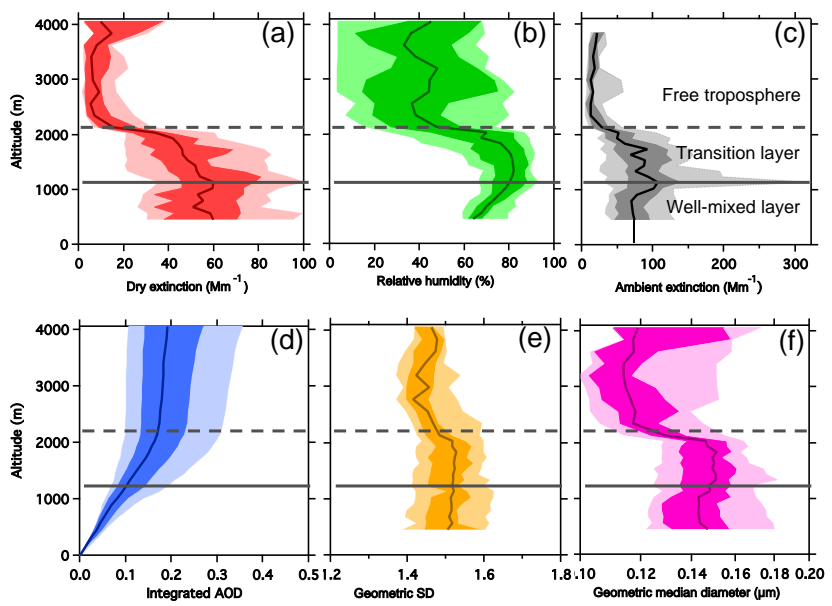

Figure 1. Aggregate vertical profiles of (a) dry extinction at standard temperature and pressure, (b) relative humidity, (c) extinction at ambient RH, pressure and temperature, (d) ambient aerosol optical depth integrated from the surface upward to the indicated altitude, and (e) number geometric median diameter and (f) geometric standard deviation for a single-mode lognormal size distribution calculated from the measured dry particle number size distribution. Light shading shows the interdecile (10 to $90 \%$ ) range, dark shading the interquartile ( 25 to $75 \%$ ) range, and the solid line the median value. The horizontal solid and dashed lines show the tops of the well-mixed and transition layers, respectively. The solid vertical line in (c) shows the extrapolation of ambient extinction to ground level to calculate AOD. Note the scale difference between (a) and (c).

here are typical of the summertime maximum in AOD found in the southeastern US (Fig. 2).

\subsection{Contribution of the well-mixed and transition layers to total AOD}

As discussed in Wagner et al. (2015), air in the transition, or cloud, layer is depleted in short-lived gas-phase tracers such as isoprene. This depletion in isoprene suggests that air parcel transport between the surface and the transition layer is slow and/or intermittent, and is probably associated with cloud outflow. The transition layer is likely composed of a combination of a residual well-mixed layer from the previous day, air that has been lifted through cloud convection above the current day's well-mixed layer, and free-tropospheric air mixed from above. Because of this relative isolation, the aerosol in the transition layer aloft may be different than that measured at the surface. In cases where the contribution of the transition layer aerosol extinction to AOD is substantial, this segregation between the transition layer and the surface adds uncertainty to efforts to directly relate remotely sensed AOD measurements to surface values, for example for epidemiological studies that use satellite-based AOD measurements as proxies for surface aerosol concentration (e.g., Crumeyrolle et al., 2014; Engel-Cox et al., 2004; Kim et al.,

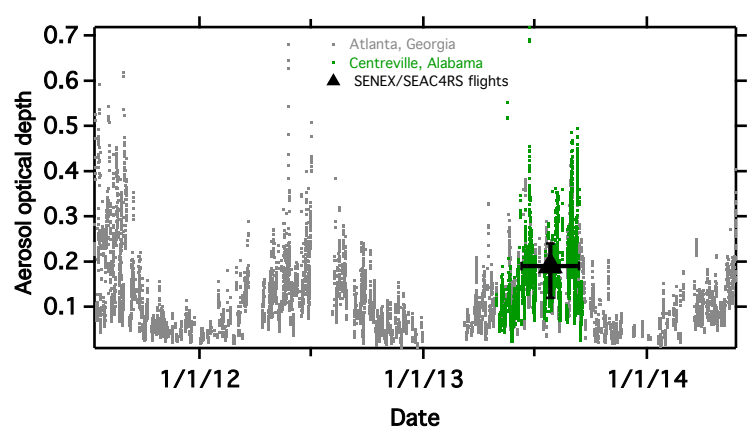

Figure 2. Atmospheric AOD measurements from the Atlanta, Georgia, and Centreville, Alabama, AERONET sunphotometer network sites using Level 2.0 data (Holben et al., 2001). The median and interquartile range for the SENEX and SEAC ${ }^{4} \mathrm{RS}$ data used in this analysis are shown by the symbol and vertical error bars, respectively.

2015; Kloog et al., 2011; van Donkelaar et al., 2015). Ultimately the transition layer and well-mixed layer aerosols are coupled through dry and moist convection, but the observed isoprene depletion in the transition layer suggests a substantial temporal lag in the response of that layer to changes to the aerosol in the well-mixed layer.

To evaluate the importance of the transition layer to AOD, the contribution of it and the well-mixed layer to total column AOD was examined for each altitude-normalized profile that penetrated both layers. The AOD within the wellmixed and transition layers was then calculated and compared with the total integrated AOD from the profile. The fractional contribution of the free-troposphere layer to the total AOD was not calculated because only 5 of the 37 profiles penetrated far enough into the free troposphere to reasonably estimate the AOD from this layer. Histograms of the total AOD and the fractional contribution of the well-mixed and transition layers (Fig. 3) show that both layers contributed substantially to the column AOD. The mean fractional contributions of the well-mixed and transition layers to total AOD were 0.56 and 0.43 , respectively, while the median fractional contributions were 0.54 and 0.43 , respectively. These results demonstrate that the transition layer, which is not in immediate contact with the surface, contributed nearly half of the integrated AOD in the southeastern US during the SENEX and SEAC ${ }^{4} \mathrm{RS}$ measurements. The substantial fraction of AOD provided from this layer aloft may affect correlations between surface aerosol concentrations and satellite-derived AOD, and should be investigated more systematically.

\subsection{Sensitivity of AOD to measured parameters}

As described in Sect. 3.1, the aggregation of individual vertical profiles results in a single vertical profile and interdecile range that represents typical midday conditions in the summertime in the southeastern US. This aggregate profile and variability range is used to estimate the sensitivity of the re- 

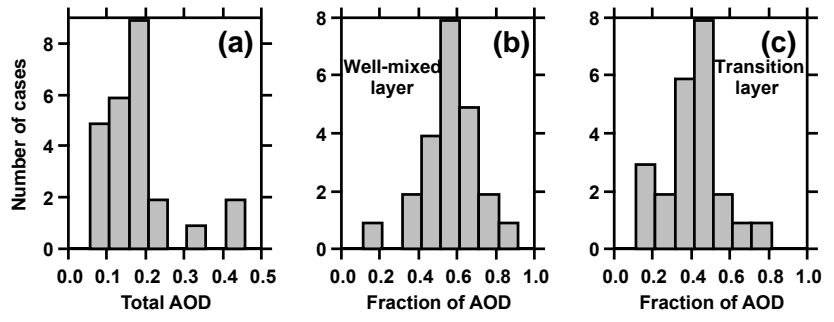

Figure 3. (a) Histogram of the AOD values integrated from the surface upward from individual profiles of aerosol extinction. (b) Histogram of the fractional contribution of the well-mixed layer to the total AOD from each case in (a). (c) As in (b), but for the fraction contribution from the transition layer.

lationship between AOD and dry mass to changes in measured parameters that affect AOD. These sensitivity calculations indicate which parameters are most important to accurately relate AOD and non-water aerosol mass in this region and season.

For the sensitivity calculations we use a single-mode lognormal model to describe the size distribution of the optically active accumulation mode aerosol. The geometric mean diameter $D_{\mathrm{g}}$, geometric standard deviation $\sigma_{\mathrm{g}}$, and total particle number concentration $N$ for this lognormal model were calculated from the measured size distributions following Hinds (1999). Prior to calculating these values, the size distributions were corrected using the refractive index based on the aerosol composition measurements, the composition model of Zaveri (2005), and the simulated response of the UHSAS instrument as a function of refractive index as described in detail in Brock et al. (2016). Mie theory for homogeneous spheres (Bohren and Huffman, 1998) was used to calculate the ambient extinction from the lognormal model distribution. For each sensitivity case the ambient extinction profile was determined using the median profiles of $\mathrm{RH}, \kappa_{\mathrm{ext}}$, $D_{\mathrm{g}}$, and $\sigma_{\mathrm{g}}$ and $N$. To determine the sensitivity of AOD to a particular parameter, the 10th and 90th percentile profiles of the tested parameter were used to recalculate ambient extinction, which was then integrated to determine the 10th and 90th percentile AOD value. All other dry parameters were maintained at the median profile while the one tested parameter was varied. As RH was varied, ambient particle diameter and refractive index were allowed to change due to water uptake and loss using $\kappa$-Köhler theory and the $\kappa_{\text {chem }}$ determined from the aerosol composition measurements as described in Brock et al. (2016). The ambient extinction profile was then calculated using Mie theory and the calculated ambient particle size distribution and refractive index. Finally, AOD for that sensitivity case was determined by integrating the vertical profile of calculated ambient extinction.

To evaluate the sensitivity of AOD to dry aerosol mass, the AMS mass concentration profiles were calculated and the number of particles in the model size distribution were varied to match the mass concentration. Since $D_{\mathrm{g}}$ and $\sigma_{\mathrm{g}}$ were held at their median profile values, this simply changed the number concentration of particles, which should produce a linearly proportional change in AOD with dry aerosol mass.

Note that these sensitivity tests do not account for covariance of parameters that might be expected in the atmosphere. For example, larger dry particle diameters might be associated with a more sulfate-rich, more hygroscopic aerosol. The sensitivity evaluations simply describe the firstorder response of AOD to changes in the interdecile range of a single parameter, with all other dry parameters being held constant using the median profile for each. More sophisticated model simulations, for example using a large eddy simulation model with aerosol input parameters constrained by observations, could be used to further investigate these sensitivities and the couplings between parameters.

The median AOD calculated from the lognormal size distribution profile was 0.18 , similar to the value of 0.19 directly determined from the in situ measurements of aerosol extinction. As expected, AOD was linearly sensitive to variations in aerosol mass (Fig. 4, Table 1). Aerosol optical depth was also highly sensitive to RH as it varied between the 10th and 90th percentile profile, with a variation in AOD of +72 and $-23 \%$ relative to the median value. This strong response in AOD to RH occurred while the altitude-averaged mean value of the extinction-weighted RH varied from 59 to $88 \%$ RH for the 10th and 90th percentile profiles. These results show that variability in $\mathrm{RH}$ is large, which propagates nonlinearly to aerosol water. As has been previously found (e.g., Adams et al., 2001; Haywood et al., 1997), aerosol water is an important and variable contributor to aerosol extinction that has a strong effect on the relationship between dry particle mass concentration, AOD and direct radiative forcing.

Aerosol optical depth was less sensitive to $D_{\mathrm{g}}$ and $\sigma_{\mathrm{g}}$ $(+21 /-19 \%$ and $+15 /-20 \%$, respectively) as they were varied between their 10th and 90th percentile profiles, largely because these parameters did not vary much in our data. For comparison with more diverse literature values, the symbol in Fig. 4 shows the AOD calculated by assuming $\sigma_{\mathrm{g}}=1.8$ prescribed by the Modal Aerosol Model (MAM) as incorporated into the CAM-Chem earth system model (Liu et al., 2012). The AOD calculated using this $\sigma_{\mathrm{g}}$ value is higher than the observed median AOD by $27 \%$. Values of $\sigma_{\mathrm{g}}$ of 2.0 are commonly used in global simulations of aerosol radiative effects (e.g., Adams et al., 2001), although it has been pointed out by Nemesure et al. (1995) that such $\sigma_{\mathrm{g}}$ values are probably unrealistically high and do not represent most observations. Given the sensitivity of AOD to the particle size distribution, it is clearly important that both models and retrieval algorithms use values that are constrained by in situ observations for the aerosol type being investigated. In moderately polluted and background conditions (excepting cases dominated by dust and sea salt), $\sigma_{\mathrm{g}}$ values larger than $\sim 1.6$ for the accumulation mode aerosol generally are not supported by observations (e.g., Brock et al., 2011; Kotchenruther et 
Table 1. AOD calculated from sensitivity tests.

\begin{tabular}{|c|c|c|c|c|c|c|}
\hline \multirow[t]{2}{*}{ Parameter varied } & \multicolumn{3}{|c|}{$\begin{array}{l}\text { Extinction-weighted }^{\mathrm{a}} \\
\text { parameter value }\end{array}$} & \multicolumn{3}{|c|}{$\begin{array}{l}\text { Calculated AOD } \\
\text { percentile values }\end{array}$} \\
\hline & 10th & 50 th & 90th & 10th & 50 th & 90th \\
\hline Dry aerosol mass $\left(\mu \mathrm{g} \mathrm{m}^{-3}\right)$ & 6.2 & 12.6 & 17.4 & 0.082 & 0.177 & 0.253 \\
\hline Relative humidity (\%) & 58.8 & 74.7 & 87.9 & 0.137 & 0.177 & 0.305 \\
\hline Number geometric mean diameter $(\mu \mathrm{m})$ & 0.125 & 0.146 & 0.171 & 0.144 & 0.177 & 0.214 \\
\hline Geometric standard deviation & 1.42 & 1.51 & 1.60 & 0.141 & 0.177 & 0.204 \\
\hline Dry refractive index: real & 1.545 & 1.549 & 1.551 & 0.173 & $0.175^{\mathrm{b}}$ & 0.178 \\
\hline imaginary & 0.004 & 0.007 & 0.011 & & & \\
\hline Ambient refractive index: real & 1.409 & 1.450 & 1.47 & 0.149 & 0.177 & 0.194 \\
\hline Imaginary & 0.004 & 0.007 & 0.011 & & & \\
\hline$\kappa_{\text {ext }}$ & 0.077 & 0.116 & 0.185 & 0.168 & 0.177 & 0.200 \\
\hline Mixed-layer height ${ }^{\mathrm{c}}(\mathrm{m})$ & 113 & 1132 & 1433 & 0.161 & 0.163 & 0.164 \\
\hline
\end{tabular}

al., 1999; Nemesure et al., 1995; Rissler et al., 2006; Vakkari et al., 2013).

Variation in the ambient refractive index profile, which is dominated by the addition of water, had a smaller effect on AOD, as did the variation in the hygroscopicity parameter $\kappa_{\text {ext }}$. The calculated AOD was not sensitive to variation in the dry real refractive index of the aerosol because of the very small range observed in this parameter for the organicdominated aerosol encountered in the southeastern US. Similarly, the change in AOD associated with the observed range of profiles of the imaginary component of the refractive index was insignificant due to the low concentrations of black carbon observed.

An additional calculation was made to evaluate the change in AOD due to the choice of hygroscopicity model, e.g., $\gamma$ (Eq. 2) vs. $\kappa_{\text {ext }}$ (Eq. 3). In this sensitivity test, the AOD was determined from ambient extinction first using the median profile of $\gamma$, and then the median profile of $\kappa_{\text {ext }}$, and the difference between these AODs was calculated. The choice of hygroscopicity model produced a change in calculated AOD about half that from measured variability in $D_{\mathrm{g}}$ and $\sigma_{\mathrm{g}}$ (Fig. 4, Table 1). The $\gamma$ parameterization produced on average more hygroscopic growth and a larger AOD than did the $\kappa_{\text {ext }}$ parameterization. This larger AOD is due to an overprediction of aerosol water content and related extinction between $\sim 60$ and $90 \% \mathrm{RH}$ by the $\gamma$ parameterization (Brock et al., 2016).

A final test was made of the sensitivity of AOD to variations in the thickness of the well-mixed layer under conditions of total columnar aerosol mass loading (i.e., constant sources and sinks). This test was made because regionalscale models often have difficulty simulating the height of the well-mixed layer (e.g., Kim et al., 2015; Scarino et al.,
2014). If the aerosol were dry, variations in boundary layer height would not affect AOD much, because the increasing height of well-mixed layer would be compensated for by dilution of the aerosol (assuming the air being mixed in during mixed-layer growth does not contribute to extinction within the layer). However, as the well-mixed layer increases in height, the temperature in the upper part of the layer decreases with the lapse rate, causing an increase in RH. Thus, for the same columnar dry aerosol mass loading, a growing well-mixed layer might increase AOD. Compensating for this increased aerosol water is a reduction in ambient aerosol concentration, and hence extinction, due to decreasing mean air density as the layer grows in altitude.

We simulate this effect with a simple model constrained by our observations. An aerosol was assumed to be perfectly mixed within the well-mixed layer, with a resulting dry extinction that decreased as atmospheric density decreased with altitude. The dry extinction at the bottom of the well-mixed layer was the median value at the lowest layer of the aggregate profile (Fig. 1a). Ambient extinction at each level in the well-mixed layer was calculated using Eq. (2), a fixed value of $\kappa_{\text {ext }}$ of 0.082 , and the median profile of RH (Fig. 1b). The height of the mixed layer was allowed to vary from 113 to $1433 \mathrm{~m}$, while the AOD of the transition layer was assumed to remain constant at the mean value of 0.081 . The contribution of the aerosol in the free troposphere to AOD was ignored. The AOD integrated through the depth of the wellmixed layer varied from 0.082 (most shallow layer) to 0.079 (deepest layer). The decrease in ambient concentration with height more than compensated for the increased extinction due to higher RH as the height of the well-mixed layer increased. Compared to the total AOD, the resulting variability in AOD due to the change in height of the well mixed layer 


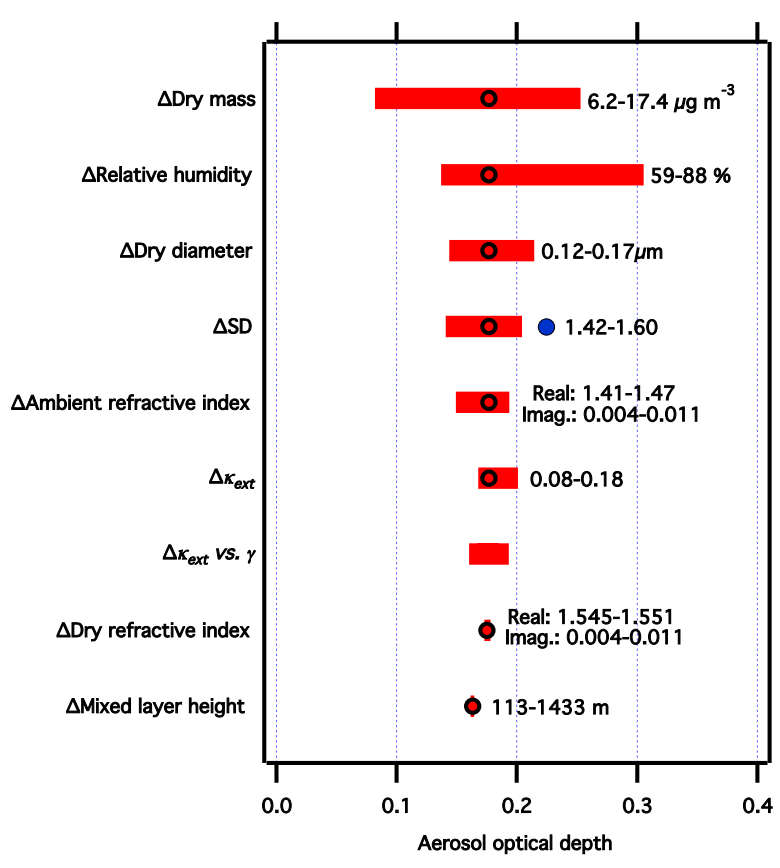

Figure 4. Range in AOD at a wavelength of $532 \mathrm{~nm}$ due to variations in measured parameters. AOD values integrated from profiles using a model aerosol size distribution and the 10th and 90th percentile range of observed aerosol and meteorological parameters (bars) and from the median profile (black circles). Numerical values show the extinction-weighted 10th-90th percentile range of the indicated parameter. The " $\kappa$ ext vs. $\gamma$ " bar describes the change in AOD associated with choice of hygroscopicity model, centered on the median AOD. The " $\triangle$ Mixed layer height" numerical values show the range in the simulated height of the well-mixed layer. The blue symbol on the " $\Delta \mathrm{SD}$ " line shows calculated AOD using a fixed geometric standard deviation of 1.8 as prescribed in the Modal Aerosol Model used in the CAM-Chem earth system model (Liu et al., 2012).

was $\pm 1 \%$. Thus, despite the increase in RH with altitude, the effect of variability in the height of the well-mixed layer on total AOD was negligible.

\section{Discussion and conclusions}

There has been considerable research on the effects of aerosol optical, microphysical, and chemical properties on aerosol extinction and AOD based on in situ measurements, laboratory studies, and modeling. However, few studies have systematically investigated the sensitivity of AOD to variations in the aerosol and meteorological parameters such as RH. Hegg et al. (1993) examined the sensitivity of ambient extinction to particle diameter and refractive index. Hegg et al. found that, as the dry aerosol humidified and grew, variations in the dry mass median diameter relative to the extinction efficiency curve produced substantial $f(\mathrm{RH})$ variability. Decreasing refractive index due to water uptake was a sec- ondary contributor. Koloutsou-Vakakis et al. (1998) found that insoluble (presumably organic) material played an important role in both dry and ambient extinction, and that the difference between efflorescence and deliquescence branches of the hygroscopicity curves was important to consider when relating aerosol mass concentration measurements to ambient scattering. Magi et al. (2005) used airborne in situ measurements in the eastern US to estimate the contribution of dry particulate constituents and aerosol water to AOD. They found that aerosol water contributed between $38 \pm 8$ and $55 \pm 15 \%$ of the total AOD, depending upon the hygroscopic growth model used. These numbers can be compared to our observations, which show an enhancement in AOD of 54 and $85 \%$ above the dry AOD when aerosol water content is included using our median profiles and the $\kappa_{\text {ext }}$ and $\gamma$ parameterizations, respectively.

Analysis of data from NASA's Deriving Information on Surface Conditions from Column and Vertically Resolved Observations Relevant to Air Quality (DISCOVER-AQ) airborne program has shown a strong relationship between AOD and surface and in situ aerosol mass concentrations in the eastern US (Crumeyrolle et al., 2014). Ziemba et al. (2013) found that aerosol water (using the $\gamma$ hygroscopic growth parameterization) was an important component of the extinction profile measured by lidar and in situ measurements in the eastern US. In contrast to these studies, we have focused on the sensitivity of AOD to RH and to aerosol properties. Our analysis suggests that it is critical to properly account for RH and its vertical distribution to quantitatively relate remotely sensed AOD to in situ aerosol properties such as mass. Within the range of variability observed during the SENEX and SEAC ${ }^{4}$ RS projects, the geometric mean diameter and standard deviation were roughly equal contributors to AOD variability. However, in some numerical models (e.g., Adams et al., 2001; Liu et al., 2012) the prescribed choices for the width of the aerosol size distribution fall outside the range of our observations, leading to potential biases in AOD that exceed $25 \%$ (Fig. 4). The AODweighted values of $\sigma_{\mathrm{g}}$ ranged from 1.35 to 1.61 in our measurements, consistent with those reported in the eastern US by Magi et al. (2005) and with other recent literature (e.g., Brock et al., 2011; Rissler et al., 2006; Vakkari et al., 2013). Substantially larger values of $\sigma_{\mathrm{g}}$ may not be appropriate for the southeastern US or other moderately polluted midlatitude and background continental environments, and may bias the AOD-dry mass relationship and lead to errors in the calculated radiative balance and associated feedbacks.

The sensitivities of AOD to $\mathrm{RH}$, to the mean diameter and width of the size distribution, and to the hygroscopicity model indicate the need for a more systematic investigation. Numerical models that incorporate aerosol radiative forcing need to be constrained by observations similar to those reported here in other types of environments, especially the dust, sea salt, biomass burning, and heavily polluted cases that globally dominate aerosol direct radia- 
tive effects (Jacobson, 2001; Kahn, 2011). One effort, Systematic Aircraft Measurements to Characterize Aerosol Air Masses (SAM-CAAM), has been proposed to make repeated measurements of critical in situ and remotely sensed parameters in a wide range of air mass types across the globe (Kahn, 2013). A comprehensive observational program such as SAM-CAAM could help disentangle the relationship between in situ aerosol and meteorological properties and AOD in different air masses, and, coupled with model and measurement refinement, reduce uncertainty in direct aerosol radiative effects.

Author contributions. All authors contributed measurements and/or analyses for this manuscript. Charles A. Brock prepared the manuscript with substantial contributions from Nicholas L. Wagner, Timothy D. Gordon, Jose L. Jimenez, Pedo Campuzano-Jost, Ann M. Middlebrook, and Daniel M. Murphy.

Acknowledgements. This work was supported in part by NOAA's Health of the Atmosphere and Atmospheric Chemistry, Carbon Cycle, and Climate Programs. Pedro Campuzano-Jost, Douglas A. Day, and Jose L. Jimenez were supported by NASA award NNX12AC03G/NNX15AH33A and NSF award AGS-1243354. Annmarie G. Carlton was supported by NSF award AGS-1242155. We thank Gary Gimmestad and Brad Gingrey for their effort in establishing and maintaining the Georgia Tech and SEARCHCentreville AERONET sites, respectively.

Disclaimer. This publication's contents do not necessarily represent the official views of the respective granting agencies. The use or mention of commercial products or services does not represent an endorsement by the authors or by any agency.

Edited by: A. Petzold

\section{References}

Adams, P. J., Seinfeld, J. H., Koch, D., Mickley, L., and Jacob, L.: General circulation model assessment of direct radiative forcing by the sulfate-nitrate-ammonium-water inorganic aerosol system, J. Geophys. Res., 106, 1097-1111, 2001.

Attwood, A. R., Washenfelder, R. A., Brock, C. A., Hu, W., Baumann, K., Campuzano-Jost, P., Day, D. A., Edgerton, E. S., Murphy, D. M., Palm, B. B., McComiskey, A., Wagner, N. L., Sá, S. S., Ortega, A., Martin, S. T., Jimenez, J. L., and Brown, S. S.: Trends in sulfate and organic aerosol mass in the Southeast U.S.: Impact on aerosol optical depth and radiative forcing, Geophys. Res. Lett., 41, 7701-7709, doi:10.1002/2014GL061669, 2014.

Bar-Or, R. Z., Koren, I., Altaratz, O., and Fredj, E.: Radiative properties of humidified aerosols in cloudy environment, J. Atmos. Res., 118, 280-294, doi:10.1016/j.atmosres.2012.07.014, 2012.

Benedetti, A., Morcrette, J. J., Boucher, O., Dethof, A., Engelen, R. J., Fisher, M., Flentje, H., Huneeus, N., Jones, L., Kaiser, J. W., Kinne, S., Mangold, A., Razinger, M., Simmons, A. J., and Suttie, M.: Aerosol analysis and forecast in the European Centre for Medium-Range Weather Forecasts Integrated Forecast System: 2. Data assimilation, J. Geophys. Res., 114, D13205, doi:10.1029/2008JD011115, 2009.

Bohren, C. F. and Huffman, D. R.: Absorption and Scattering of Light by Small Particles, John Wiley \& Sons, New York, NY, ISBN: 978-0-471-29340-8, 1998.

Boucher, O. and Anderson, T. L.: General circulation model assessment of the sensitivity of direct climate forcing by anthropogenic sulfate aerosols to aerosol size and chemistry, J. Geophys. Res., 100, 26117-26134, 1995.

Boucher, O., Randall, D., Artaxo, P., Bretherton, C., Feingold, G., Forster, P., Kerminen, V. M., Kondo, Y., Liao, H., Lohmann, U., P. Rasch, P., Satheesh, S. K., Sherwood, S., Stevens, B., and Zhang, X. Y.: Clouds and aerosols, in: Climate Change 2013: The Physical Science Basis. Contribution of Working Group I to the Fifth Assessment Report of the Intergovernmental Panel on Climate Change. Cambridge University Press, Cambridge, United Kingdom and New York, NY, 571-657, 2013.

Brock, C. A., Cozic, J., Bahreini, R., Froyd, K. D., Middlebrook, A. M., McComiskey, A., Brioude, J., Cooper, O. R., Stohl, A., Aikin, K. C., de Gouw, J. A., Fahey, D. W., Ferrare, R. A., Gao, R.-S., Gore, W., Holloway, J. S., Hübler, G., Jefferson, A., Lack, D. A., Lance, S., Moore, R. H., Murphy, D. M., Nenes, A., Novelli, P. C., Nowak, J. B., Ogren, J. A., Peischl, J., Pierce, R. B., Pilewskie, P., Quinn, P. K., Ryerson, T. B., Schmidt, K. S., Schwarz, J. P., Sodemann, H., Spackman, J. R., Stark, H., Thomson, D. S., Thornberry, T., Veres, P., Watts, L. A., Warneke, C., and Wollny, A. G.: Characteristics, sources, and transport of aerosols measured in spring 2008 during the aerosol, radiation, and cloud processes affecting Arctic Climate (ARCPAC) Project, Atmos. Chem. Phys., 11, 2423-2453, doi:10.5194/acp-11-24232011, 2011.

Brock, C. A., Wagner, N. L., Anderson, B. E., Attwood, A. R., Beyersdorf, A., Campuzano-Jost, P., Carlton, A. G., Day, D. A., Diskin, G. S., Gordon, T. D., Jimenez, J. L., Lack, D. A., Liao, J., Markovic, M. Z., Middlebrook, A. M., Ng, N. L., Perring, A. E., Richardson, M. S., Schwarz, J. P., Washenfelder, R. A., Welti, A., Xu, L., Ziemba, L. D., and Murphy, D. M.: Aerosol optical properties in the southeastern United States in summer - Part 1: Hygroscopic growth, Atmos. Chem. Phys., 16, 49875007, doi:10.5194/acp-16-4987-2016, 2016.

Crumeyrolle, S., Chen, G., Ziemba, L., Beyersdorf, A., Thornhill, L., Winstead, E., Moore, R. H., Shook, M. A., Hudgins, C., and Anderson, B. E.: Factors that influence surface $\mathrm{PM}_{2.5}$ values inferred from satellite observations: perspective gained for the US Baltimore-Washington metropolitan area during DISCOVERAQ, Atmos. Chem. Phys., 14, 2139-2153, doi:10.5194/acp-142139-2014, 2014.

Doherty, S. J.: A comparison and summary of aerosol optical properties as observed in situ from aircraft, ship, and land during ACE-Asia, J. Geophys. Res., 110, D04201, doi:10.1029/2004JD004964, 2005.

Engel-Cox, J., Holloman, C., Coutant, B., and Hoff, R.: Qualitative and quantitative evaluation of MODIS satellite sensor data for regional and urban scale air quality, Atmos. Environ., 38, 24952509, 2004.

Esteve, A. R., Ogren, J. A., Sheridan, P. J., Andrews, E., Holben, B. N., and Utrillas, M. P.: Sources of discrepancy between aerosol 
optical depth obtained from AERONET and in-situ aircraft profiles, Atmos. Chem. Phys., 12, 2987-3003, doi:10.5194/acp-122987-2012, 2012.

Esteve, A. R., Highwood, E. J., and Ryder, C. L.: A case study of the radiative effect of aerosols over Europe: EUCAARI-LONGREX, Atmos. Chem. Phys. Discuss., doi:10.5194/acp-2015-953, in review, 2016.

Haywood, J. M., Ramaswamy, V., and Donner, L. J.: A limitedarea-model case study of the effects of sub-grid scale variations in relative humidity and cloud upon the direct radiative forcing of the sulfate aerosol, Geophys. Res. Lett., 24, 143-146, 1997.

Hegg, D., Larson, T., and Yuen, P. F.: A theoretical study of the effect of relative humidity on light scattering by tropospheric aerosols, J. Geophys. Res., 98, 18435-18439, 1993.

Hinds, W. C.: Aerosol technology: properties, behavior, and measurement of airborne particles, 2nd Edn., John Wiley and Sons, New York, ISBN: 978-0-471-19410-1, 1999.

Holben, B. N., Tanre, D., Smirnov, A., Eck, T. F., Slutsker, I., Abuhassan, N., Newcomb, W. W., Schafer, J. S., Chatenet, B., and Lavenu, F.: An emerging ground-based aerosol climatology: Aerosol optical depth from AERONET, J. Geophys. Res., 106, 12067-12097, 2001.

Jacobson, M. Z.: Global direct radiative forcing due to multicomponent anthropogenic and natural aerosols, J. Geophys. Res., 106, 1551-1568, 2001.

Kim, P. S., Jacob, D. J., Fisher, J. A., Travis, K., Yu, K., Zhu, L., Yantosca, R. M., Sulprizio, M. P., Jimenez, J. L., CampuzanoJost, P., Froyd, K. D., Liao, J., Hair, J. W., Fenn, M. A., Butler, C. F., Wagner, N. L., Gordon, T. D., Welti, A., Wennberg, P. O., Crounse, J. D., St. Clair, J. M., Teng, A. P., Millet, D. B., Schwarz, J. P., Markovic, M. Z., and Perring, A. E.: Sources, seasonality, and trends of southeast US aerosol: an integrated analysis of surface, aircraft, and satellite observations with the GEOS-Chem chemical transport model, Atmos. Chem. Phys., 15, 10411-10433, doi:10.5194/acp-15-10411-2015, 2015.

Kahn, R. A.: Reducing the uncertainties in direct aerosol radiative forcing, Surv. Geophys, 33, 701-721, doi:10.1007/s10712-0119153-z, 2011.

Kahn, R. A.: How can we obtain global-scale, quantitative aerosol type information?, Fall Meeting of the American Geophysical Union, San Francisco, U.S., 9-13 December 2013, A53K-08, 2013.

Kasten, F.: Visibility forecast in the phase of pre-condensation, Tellus, 21, 631-635, 1969.

Kloog, I., Koutrakis, P., Coull, B. A., Lee, H. J., and Schwartz, J.: Assessing temporally and spatially resolved $\mathrm{PM}_{2.5}$ exposures for epidemiological studies using satellite aerosol optical depth measurements, Atmos. Environ., 45, 6267-6275 doi:10.1016/j.atmosenv.2011.08.066, 2011.

Koloutsou-Vakakis, S., Rood, M. J., Nenes, A., and Pilinis, C.: Modeling of aerosol properties related to direct climate forcing, J. Geophys. Res., 103, 17009-17032, 1998.

Koren, I., Remer, L. A., Kaufman, Y. J., Rudich, Y., and Martins, J. V.: On the twilight zone between clouds and aerosols, Geophys. Res. Lett., 34, L08805, doi:10.1029/2007GL029253, 2007.

Kotchenruther, R. A., Hobbs, P. V., and Hegg, D. A.: Humidification factors for atmospheric aerosols off the mid-Atlantic coast of the United States, J. Geophys. Res., 104, 2239-2251, 1999.
Liu, X., Easter, R. C., Ghan, S. J., Zaveri, R., Rasch, P., Shi, X., Lamarque, J.-F., Gettelman, A., Morrison, H., Vitt, F., Conley, A., Park, S., Neale, R., Hannay, C., Ekman, A. M. L., Hess, P., Mahowald, N., Collins, W., Iacono, M. J., Bretherton, C. S., Flanner, M. G., and Mitchell, D.: Toward a minimal representation of aerosols in climate models: description and evaluation in the Community Atmosphere Model CAM5, Geosci. Model Dev., 5, 709-739, doi:10.5194/gmd-5-709-2012, 2012.

Magi, B. I., Hobbs, P. V., Kirchstetter, T. W., Novakov, T., Hegg, D. A., Gao, S., Redemann, J., and Schmid, B.: Aerosol properties and chemical apportionment of aerosol optical depth at locations off the US East Coast in July and August 2001, J. Atmos. Sci., 62, 919-933, 2005.

Massoli, P., Bates, T., Quinn, P., and Lack, D.: Aerosol optical and hygroscopic properties during TexAQS-GoMACCS 2006 and their impact on aerosol direct radiative forcing, J. Geophys. Res., 114, D00F07, doi:10.1029/2008JD011604, 2009.

McComiskey, A., Schwartz, S. E., Schmid, B., Guan, H., Lewis, E. R., Ricchiazzi, P., and Ogren, J. A.: Direct aerosol forcing: Calculation from observables and sensitivities to inputs, J. Geophys. Res., 113, D09202, doi:10.1029/2007JD009170, 2008.

Nemesure, S., Wagener, R., and Schwartz, S. E.: Direct shortwave forcing of climate by the anthropogenic sulfate aerosol: Sensitivity to particle size, composition, and relative humidity, J. Geophys. Res., 100, 26105-26116, 1995.

Petters, M. D. and Kreidenweis, S. M.: A single parameter representation of hygroscopic growth and cloud condensation nucleus activity, Atmos. Chem. Phys., 7, 1961-1971, doi:10.5194/acp-71961-2007, 2007.

Pilinis, C., Pandis, S. N., and Seinfeld, J. H.: Sensitivity of direct climate forcing by atmospheric aerosols to aerosol size and composition, J. Geophys. Res., 100, 18739-18754, 1995.

Quinn, P. K., Bates, T. S., Baynard, T., Clarke, A. D., Onasch, T. B., Wang, W., Rood, M. J., Andrews, E., Allan, J., Carrico, C. M., Coffman, D., and Worsnop, D.: Impact of particulate organic matter on the relative humidity dependence of light scattering: A simplified parameterization, Geophys. Res. Lett., 32, L22809, doi:10.1029/2005GL024322, 2005.

Rissler, J., Vestin, A., Swietlicki, E., Fisch, G., Zhou, J., Artaxo, P., and Andreae, M. O.: Size distribution and hygroscopic properties of aerosol particles from dry-season biomass burning in Amazonia, Atmos. Chem. Phys., 6, 471-491, doi:10.5194/acp6-471-2006, 2006.

Saide, P. E., Kim, J., Song, C. H., Choi, M., Cheng, Y., and Carmichael, G. R.: Assimilation of next generation geostationary aerosol optical depth retrievals to improve air quality simulations, Geophys. Res. Lett., 41, 9188-9196, doi:10.1002/2014GL062089, 2014.

Scarino, A. J., Obland, M. D., Fast, J. D., Burton, S. P., Ferrare, R. A., Hostetler, C. A., Berg, L. K., Lefer, B., Haman, C., Hair, J. W., Rogers, R. R., Butler, C., Cook, A. L., and Harper, D. B.: Comparison of mixed layer heights from airborne high spectral resolution lidar, ground-based measurements, and the WRFChem model during CalNex and CARES, Atmos. Chem. Phys., 14, 5547-5560, doi:10.5194/acp-14-5547-2014, 2014.

Twohy, C. H., Coakley Jr., J. A., and Tahnk, W. R.: Effect of changes in relative humidity on aerosol scattering near clouds, J. Geophys. Res., 114, D05205, doi:10.1029/2008JD010991, 2009. 
Vakkari, V., Beukes, J. P., Laakso, H., Mabaso, D., Pienaar, J. J., Kulmala, M., and Laakso, L.: Long-term observations of aerosol size distributions in semi-clean and polluted savannah in South Africa, Atmos. Chem. Phys., 13, 1751-1770, doi:10.5194/acp13-1751-2013, 2013.

van Donkelaar, A., Martin, R. V., Brauer, M., and Boys, B. L.: Use of satellite observations for long-term exposure assessment of global concentrations of fine particulate matter, Environ. Health Persp., 123, 135-143, doi:10.1289/ehp.1408646, 2015.

Wagner, N. L., Brock, C. A., Angevine, W. M., Beyersdorf, A., Campuzano-Jost, P., Day, D., de Gouw, J. A., Diskin, G. S., Gordon, T. D., Graus, M. G., Holloway, J. S., Huey, G., Jimenez, J. L., Lack, D. A., Liao, J., Liu, X., Markovic, M. Z., Middlebrook, A. M., Mikoviny, T., Peischl, J., Perring, A. E., Richardson, M. S., Ryerson, T. B., Schwarz, J. P., Warneke, C., Welti, A., Wisthaler, A., Ziemba, L. D., and Murphy, D. M.: In situ vertical profiles of aerosol extinction, mass, and composition over the southeast United States during SENEX and SEAC ${ }^{4}$ RS: observations of a modest aerosol enhancement aloft, Atmos. Chem. Phys., 15, 7085-7102, doi:10.5194/acp-15-7085-2015, 2015.
Warren, S. G., Eastman, R. M., and Hahn, C. J.: A Survey of Changes in Cloud Cover and Cloud Types over Land from Surface Observations, 1971-96, J. Climate, 20, 717-738, doi:10.1175/JCLI4031.1, 2007.

Zaveri, R. A.: A new method for multicomponent activity coefficients of electrolytes in aqueous atmospheric aerosols, J. Geophys. Res., 110, D02201, doi:10.1029/2004JD004681, 2005.

Ziemba, L. D., Hudgins, C. H., Obland, M. D., Rogers, R. R., Scarino, A. J., Winstead, E. L., Anderson, B. E., Thornhill, K. L., Ferrare, R., Barrick, J., Beyersdorf, A. J., Chen, G., Crumeyrolle, S., Hair, J., and Hostetler, C. A.: Airborne observations of aerosol extinction by in-situ and remote-sensing techniques: Evaluation of particle hygroscopicity, Geophys. Res. Lett., 40, 417-422, doi:10.1029/2012GL054428, 2013. 